\title{
Low impact of forest conversion on biodiversity: evidence from small mammals in contrasting forests of Mt. Liangshan, China
}

\author{
He Xingcheng ${ }^{1}$, Zhixin Wen ${ }^{2}$, Zhang Dejun ${ }^{3}$, Yin Xudong ${ }^{3}$, Chen $x^{3}{ }^{3}$, and Jianghong Ran ${ }^{4}$ \\ ${ }^{1}$ Sichuan University School of Life Sciences \\ ${ }^{2}$ Institute of Zoology Chinese Academy of Sciences \\ ${ }^{3}$ Sichuan University - Wangjiang Campus \\ ${ }^{4}$ Sichuan University
}

November 15, 2021

\begin{abstract}
Secondary and plantation forests are the main alternative forests remaining after the deforestation of primary forests. Understanding the conservation value of secondary and plantation forests is important for resource utilization. To explore the impact of forest conversion on biodiversity, we compared multiple diversity metrics (taxonomic, phylogenetic and functional diversity) and community structures of small mammals in the primary, secondary and plantation forests on Mt. Liangshan, Sichuan Province, China. Seven field surveys were conducted to survey local small mammal assemblages between 2016 and 2020 . We found that the taxonomic, phylogenetic and functional diversity metrics of small mammals in the three forest types were similar at the landscape scale, while all diversity metrics were lowest in the plantation forest and highest in the primary forests at the site scale. The community structure analysis showed that random processes were dominant across the three forest types, and there was no difference in small mammal community structures among the three forest types. Our results indicated that secondary and plantation forests in the nature reserves, adjacent to the primary forest and exposed to little human disturbance, also can provide important habitats for small mammals.
\end{abstract}

\section{Introduction}

During the past 40 years, large areas of primary forests in China have been rapidly logged and converted to secondary and plantation forests due to economic development (Jian et al., 2011). Forest conversion could directly or indirectly affect species distributions and the composition of biological communities (Meiners \& Pickett, 1999; Suchomel et al., 2014; Tinya et al., 2021), resulting in significant changes in the structure of forestry biotic communities and associated ecosystem services (Hughes, 2017; Zhang et al., 2020). Primary forests can be climax or subclimax forests, where dominant trees are close to or older than their age at physiological maturity (Hilbert \& Wiensczyk, 2007; Morales-Hidalgo et al., 2015). Secondary forests can be understood as a degradation of the primary forests and differ from primary forests in many respects, such as vegetation structure, primary productivity and ecological function (Grau et al., 1997). Plantation forests usually consist of one or several indigenous or exotic tree species that grow rapidly, with a simple vegetation structure and high tree abundance (Felton et al., 2008). Numerous studies have demonstrated that primary forests play an indispensable role in the conservation of birds (Lindenmayer et al., 2015; Manuwal \& Huff, 1987), plants (Kosulic et al., 2020), carabids (Elek et al., 2001; Magura et al., 2015), moths (Luque et al., 2007) and small mammals (Umetsu et al., 2007; Bogdziewicz et al., 2014; Rebelo et al, 2019) especially those that are forest-dependent or/and endemic. However, some studies have shown that the diversity of plants (Graham et al., 2019), small mammals (Suchomel et al 2012; Suchomel et al., 2014; Heer et al., 2015), and birds (Zhang et al., 2020) in secondary and plantation forests were equal to or even higher than that in 
primary forests, especially in heterogeneous landscape regions where secondary and plantation forests are distributed adjacent to primary forests (Bernard et al., 2009; Yang et al., 2015; Zhang et al., 2020).

Small mammals play an important role in food web dynamics (Ernest \& Brown, 2001; Wu et al., 2019). Insectivores that prey on invertebrates (e.g., insects) can significantly affect the functioning of forest ecosystems, and herbivorous species (e.g., Tamiops swinhoei) (including granivores and frugivores) serve as seed dispersers (Urgoiti et al., 2018). On the other hand, they are prey for birds, reptiles and large mammals (Chubbs \& Trimper, 1998; Dawson \& Bortolotti, 2000; Zhao et al., 2020). In addition, small mammals are easy to investigate and characterized by low dispersal ability and strong ecological adaptability. Consequently, small mammals are usually treated as ecological indicators of environmental change (Carey \& Johnson, 1995; Ernest \& Brown, 2001), making them ideal models for examining the effects of forest compositional change on biodiversity and community structures (Carey \& Johnson, 1995).

Although taxonomic diversity (TD) is the most commonly used metric for assessing the conservation values of different regions, limitations exist in its ability to locate the conservation priority area because it implicitly treats all species equally (Davis et al. 2018). In nature, species perform different ecological functions in an ecosystem and have different degrees of phylogenetic relatedness. Therefore, functional diversity (FD) and phylogenetic diversity (PD), which take into account the functional traits and species-specific evolutionary history respectively, have been suggested as important diversity metrics in conservation biology (Diaz \& Cabido, 2001; Diaz et al., 2013). In addition, understanding the processes of community assembly and the underlying mechanisms community assembly are important for the development of conservation rules. With the development of statistical methodology, it has become possible to quantify the relative importance of habitat filtering, interspecific competition and neutral assembly in community assembly based on the phylogenetic and functional information of species (Montano-Centellas et al., 2020; Webb et al., 2002; Zhang et al., 2020).

For small mammals, most previous studies comparing diversity and community structures between different forest types (e.g., primary, secondary, and plantation forests) did not consider the effect of seasonality (Rebelo et al., 2019; Wu et al., 2019). Because resource availability (e.g., leaves, fruits and seeds) and habitat structures (e.g., crown density, herb coverage and shrub coverage; Williams et al., 2010) in a forest vary among seasons, seasonality should be taken as an important covariate in elucidating species diversity pattern and community assembly (Hurlbert \& Haskell, 2003). Therefore, integrated studies comparing the TD, FD, PD and community structures of small mammals among seasons are valuable to replenish our understanding how forest conversion affects small mammal diversity and community structures. Unfortunately, such studies are extremely rare (but see Pedersen et al., 2010).

Mt. Liangshan, located in the southwestern part of Sichuan Province, have large areas of primary forests. However, primary forests in Mt. Liangshan were logged heavily and converted to secondary and plantation forests due to the increasing demand for timber during the $1960 \mathrm{~s}-1970 \mathrm{~s}$. With the establishment of nature reserves and the implementation of policy of prohibiting logging (e.g. the Natural Forest Protection Program), all forests in the nature reserves, protected by law then and therefore, were exposed to little human disturbance. Zhang et al. (2020) assessed the differences in three dimensions of avian diversity (TD, FD and PD) and community structures among the primary, secondary and plantation forests in the Meigu Dafengding Nature Reserve in Mt. Liangshan. They found that TD, FD and PD in the secondary forests were significantly greater than those in the primary forests. In addition, habitat filtering was the dominant process in the primary forests. However, these results cannot be simply extrapolated to other taxa because the taxa in an ecosystem generally differ in their evolutionary histories and ecological service functions.

In this study, using a robust dataset obtained from four-years field survey, we studied small mammal diversity (TD, FD and PD) and community structures in the primary, secondary and plantation forests in Mt. Liangshan. We aimed to answer the following two questions:

Are small mammal taxonomic, functional and phylogenetic diversity affected by forest conversion?

Do the ecological processes structuring small mammal communities differ among the three types of forests? 


\section{Methods}

\subsection{Study area}

Our study area consists of two nature reserves (Heizhugou Nature Reserve, 28 40'-29deg10'N, 102deg50'103deg10', and Meigu Dafengding Nature Reserve, 28deg30'-28deg50' N, 102deg52'-103deg20'E) in Mt. Liangshan (Fig. 1). This area is within a global biodiversity hotspot (i.e. the Hengduan Mountains, Mittermeier et al., 2005) and features a subtropical monsoon humid climate with elevations ranging from $1054-4288 \mathrm{~m}$.

Our study region has large areas of primary, secondary and plantation forests. Primary forests are scattered along the mountain ridges in the Heizhugou Nature Reserve and in the northeastern core area of the Meigu Dafengding Nature Reserve. Secondary forests, consisting mainly of second-growth broad-leaved trees, were allowed to recover naturally. Tree species of Pinaceae, Fagaceae and Cornaceae are dominant in the oldgrowth and secondary forests. Plantation forests were first planted on the land after large-scale deforestation during the 1970s and are now distributed throughout the Meigu Dafengding Nature Reserve and Heizhugou Nature Reserve. The predominant plant species in the plantation forests are Cunninghamia lanceolata, Picea asperata and Abies fabri.

\subsection{Sampling of small mammals}

Small mammals, including glires (Rodentia and Lagomorpha) and insectivores (Eulipotyphla), were sampled seven times in the three forest types from 2017 to 2020 (four surveys in the Meigu Dafengding Nature Reserve and three surveys in the Heizhugou Nature Reserve). During each survey, three sample sites were placed at $2200 \mathrm{~m}, 2600 \mathrm{~m}$, and $3000 \mathrm{~m}$ a.s.l. for each forest type (a total of 54 sample sites), and each sample sites were at least $500 \mathrm{~m}$ away from each other. In June 2017, September 2017, March 2018 and June 2018, 27 sample sites were set in Meigu Dafengding Nature Reserve. In April 2020, July 2020, and October 2020, 27 sample sites were set in Heizhugou Nature Reserve.

At each sample site, 49 trap stations were evenly spaced in seven rows and spaced $5 \mathrm{~m}$ apart, with each station consisting of a snap trap $(155 \times 85 \mathrm{~mm})$. Two additional trap stations consisting of two plastic buckets $(450 \times 300 \mathrm{~mm})$ and one plastic sheet $(8 \times 1 \mathrm{~m})$ were set up at each site. The plastic sheet was fixed vertically to the ground and perpendicular to other sheets, and the two plastic buckets were buried at each end of the plastic sheet (Liang, Dai, \& Li, 2008). We used fresh peanuts as the bait for snap traps which were during the following morning (8:00 am-11:00 am). Each bucket was filled with $300-500 \mathrm{ml}$ of water to prevent small mammals from escaping. All traps were set for three consecutive days at each site. Our manipulation was in accordance with the National Wildlife Conservation Law of China.

All captured individuals were measured, and we recorded information of body length (mm), body mass $(\mathrm{g})$, ear length $(\mathrm{mm})$, tail length $(\mathrm{mm})$, sex, and hind foot length $(\mathrm{mm})$. All tissues and specimens were deposited at the Nature Museum of Sichuan University. The taxonomic system used in this study followed that for China's mammals diversity and geographic distribution (Jiang et al., 2015).

\subsection{Community phylogeny and functional traits of small mammals}

We extracted the phylogenies of the species in the dataset from a recently published supertree of small mammals (Faurby et al., 2018). We downloaded 10000 final trees from http://vertlife.org/phylosubsets/. Subsequently, we sampled 5000 pseudoposterior distributions and constructed a maximum clade credibility tree using the mean node heights in TreeAnnotator v1.10.4 software of the BEAST package. The resulting tree was used for all subsequent phylogenetic analyses (Fig. S1).

Eight commonly used small mammal functional traits were selected for analysis: (1) body length (mm), 2) body mass $(\mathrm{g}), 3)$ ear length $(\mathrm{mm}), 4)$ tail length $(\mathrm{mm}), 5)$ hind foot length $(\mathrm{mm}), 6)$ diet (herbivore and insectivore), 7) foraging stratum (ground and non-ground), and 8) daily activity (nocturnal, crepuscular and diurnal) (Sun et al., 2020). The morphological trait data of a species was calculated as the average value of all its captured individuals, and other traits were compiled from Elton Traits 1.0 (Appendix; Wilman et 
al., 2014). To create the functional distance matrix (Gower distance), we used the function "vegdist" in the R package "vegan" (Oksanen et al. 2012). We clustered the functional distance matrix and obtained a functional dendrogram (Fig. S2). The resulting tree was used for all subsequent functional analyses (Fig. $\mathrm{S} 2)$.

We quantified the phylogenetic signals to identify possible differences in the patterns of functional and phylogenetic structures. If a significant phylogenetic signal is detected for a trait, it means that the trait is more similar among closely related species than expected by chance (Revell et al., 2008). For continuous traits, the phylogenetic signal was quantified using the K statistic. K [?] 1 suggests the presence of a phylogenetic signal. $\mathrm{K}$ close to zero suggests the presence of a weak phylogenetic signal (Blomberg et al., 2003). For binary traits, the D statistic was used to quantify the phylogenetic signal. If D approaches 0 , there is conserved trait evolution, whereas $\mathrm{D}<0$ suggests trait clustering. A value of $\mathrm{D}$ [?] 1 indicates no phylogenetic signal or a trait that is overdispersed on the phylogenetic tree (Fritz \& Purvis, 2010). The D statistic and K statistic were calculated by using the "phylo.d" and "multiPhylosignal" functions in the R packages "caper" and "picante", respectively (Kembel et al., 2010; Orme et al., 2013).

\subsection{Diversity and community structure metrics}

In this study, we calculated the TD, FD and PD of small mammals. Besides, we used landscape diversity indices (calculated by all species recorded in each forest landscape using six surveys' data) and site diversity indices (calculated by six-surveys data recorded at one sample site; to maintain the consistency of sampling efforts, we did not use the survey data for the Meigu Dafengding Nature Reserve in June 2017) to understand small mammal diversity at different scales (all of sample sites were sampled three times). TD was calculated as the total number of species in each forest type (species richness). We used the function "specaccum" in the R package "vegan" to compare the rarefaction curves of species richness. PD and FD were calculated as the average of Faith's index, where Faith's index is the sum of branch lengths of the phylogenetic or functional tree for all species within a given community (Faith, 1992). We used the function "pd.query" in the R package "PhyloMeasures" to calculate PD and FD (Tsirogiannis, 2016).

We used the function "ses.mpd" and the null model "taxa.labels" in the R package "picante" to compute the standardized effect size of mean phylogenetic distances (SES.MPD), which represented the phylogenetic relatedness of small mammal assemblages (Webb et al., 2002). A positive value of SES.MPD indicates that the small mammal community is more distantly related than expected (overdispersed) because of interspecific competition, while a negative value of SES.MPD indicates that the small mammal community is more closely related than expected (clustered) because of environmental filtering (Webb et al., 2002). SES.MPD is computed as

$$
S E S . M P D=\left(M P D_{\text {obs }}-\text { mean } \mathrm{MPD}_{\text {null }}\right) / s d \mathrm{MPD}_{\text {null }}
$$

where $\mathrm{MPD}_{\mathrm{obs}}$ is the observed mean phylogenetic distance (MPD) of small mammals in a community,meanMPD ${ }_{\text {null }}$ is the mean MPD of the null models (with distance matrix labels shuffled 999 times), andsdMPD null is the standard deviation of MPD of the null models.

We calculated the standardized effect size of mean functional distances based on the functional dendrogram, following methods similar to those used for the standardized effect size of mean phylogenetic distances.

\subsection{Statistical analysis}

According to the homogeneity of variance, one-way ANOVA or Kruskal-Wallis Tests were performed to assess the differences in small mammal diversity and community structure metrics among the three forest types. Tukey's HSD multiple comparison tests (one-way ANOVA) or Wilcoxon Rank Sum tests (KruskalWallis Tests) were performed on the means when the differences were significant. We conducted Wilcoxon tests and t-tests to assess differences between community structure metrics and 0 . We conducted a non-line ordination with multidimensional scaling (NDMS), based on Bray-Curtis similarity matrices, to assess the 
similarity of small mammal species assemblages among the three forest types (Clarke, 1993). Chi-square tests were performed to test for differences in the ratio of glire (i.e., the proportion of glire species among all small mammal species) species among the three forest types. The results were considered significant at $\mathrm{p}<0.05$. All analyses were conducted in the $\mathrm{R}$ statistical environment (version 4.05).

\section{Results}

\subsection{Community diversity}

A total of 1179 small mammal individuals were captured in our study, belonging to 30 species (Appendix), including 17 glire species (accounting for 56.7\%) and 13 insectivore species (43.3\%). The rarefaction curves showed that our survey results adequately represented the small mammal diversity in each forest type (Fig. 2). At the landscape scale, 28,24 and 27 small mammal species were recorded in the primary, secondary and plantation forests, respectively. Two species (Niviventer andersoni and Berylmys bowersi) were recorded only in the primary forests, Chodsigoa lamula was recorded only in the secondary forests, and Scaptonyx fusicauduswas the unique species sampled in the plantation forests (Appendix). All 17 glire species were recorded in the primary forests, accounting for $60.7 \%$ of the primary forest species. Thirteen glire species were recorded in the secondary forests, accounting for $54.1 \%$ of secondary forest species, while 15 glire species were recorded in the plantation forests, accounting for $55.6 \%$ of plantation forest species. There was no difference in the ratio of glire species among the three forest types (chi-squared test, $\chi^{2}=.259, d f=2$, $\mathrm{p}=0.879$ ). In addition, FD and $\mathrm{PD}$ were highest in the primary forests, followed by the plantation forests and secondary forests (Fig. 3). At the site scale, the TD, FD and PD at the plantation forest sites were significantly lower than those at the primary forest sites (one-way ANOVA: $d f=2, \mathrm{p}=0.003$; Kruskal-Wallis Test: $d f=2, \mathrm{p}=0.046$; and one way ANOVA: $d f=2, \mathrm{p}=0.043$, respectively), and there was no significant difference in TD, FD or PD between the secondary and primary forest sites (Fig. 3). In addition, NMDS ordinations of species assemblage showed that community composition of small mammals was similar among the three forest types (Fig. 4).

\subsection{Phylogenetic and functional community structures}

At the landscape scale, SES.MPD values were less than zero in all forest types, while SES.MFD values were close to (but greater than) zero. At the site scale, SES.MPD values were significantly lower than zero in all forest types (t-test, $t=-3.719, d f=17, \mathrm{p}=0.002$; t-test, $t=-2.851, d f=17, \mathrm{p}=0.011$; t-test, $t=-3.281, d f$ $=17, \mathrm{p}=0.004)$, and there was no significant difference in the SES.MPD values among the three forest types (one-way ANOVA, $d f=2, F=0.178, \mathrm{p}=0.838$ ). SES.MFD values were close to zero in forest types (Wilcoxon test, $V=111, \mathrm{p}=0.284$; t-test, $t=-0.798, d f=17, \mathrm{p}=0.436$; t-test, $t=-0.609, d f=17, \mathrm{p}=0.551$ ), and there was no significant difference in SES.MFD among forest types (one-way ANOVA, $d f=2, F=0.589, \mathrm{p}=0.559$, Fig. 5).

The $\mathrm{K}$ values of body length, tail length, hind foot length and ear length were all less than 1, indicating weak phylogenetic signals of these functional traits (i.e. trait convergence). D statistics revealed weak phylogenetic signals for foraging stratum and daily activity $\left(0<\mathrm{D}_{\text {obs }}<1\right.$; i.e. trait convergence) but strong signals for the other four binary traits $\left(\mathrm{D}_{\mathrm{obs}}<0\right.$; i.e. trait conservatism). The distributions of foraging stratum and daily activity differed significantly from random distributions along the phylogeny, while only that of daily activity differed from a Brownian distribution (Table S1).

\subsection{Seasonal dynamics}

At the landscape scale, all diversity metrics were similar among the three forest types during all seasons (Fig. 6). At the site scale, all diversity metrics (mean value) were lowest in the plantation forest and highest in the primary or secondary forests during all seasons (Fig. 6). As for community structures, in most cases, SES.MPD and SES.MFD values were close to zero, while SES.MPD values were significantly less than zero in the primary forests in spring and summer (Fig. 7).

\section{Discussion}




\subsection{Taxonomic, functional and phylogenetic diversity}

Our findings revealed no difference in the TD, PD and FD of small mammals among the three forest types at the landscape scale, indicating that secondary and plantation forests can play an important role in the maintenance of small mammal communities after deforestation. Our results were consistent with those of most previous studies on small mammals (Suchomel et al., 2012; Suchomel et al., 2014; Wu et al., 2019). The studied secondary forests, with a particularly high diversity and abundance of broadleaf vegetation, can support a higher diversity of small mammals by providing more food resources (Suchomel et al., 2014). Small mammal diversity in the studied plantation forests was slightly higher than that in the secondary forests and was similar to that in the primary forests. This phenomenon may result from two mechanisms: (1) In our study area, secondary and plantation forests are closed to the primary forests, which acts as reservoir of species (Partel et al. 1996; Bernard et al., 2009). Small mammals can spread from primary forests to secondary or/and plantation forest, resulting in the high similarity of the assemblage. (2) Although the structure and composition of vegetation in the plantation forests were simpler than those in the primary and secondary forests, some shrubs and understorey vegetation were also present in the plantation forests, which can provide food resources and shelter. Meanwhile, small mammals can quickly adapt to environmental change (Graham et al., 2019).

At the site scale, the TD, FD and PD of small mammals were highest in the primary forests and lowest in the planation forests during all three seasons. These results indicated that although small mammals can survive in the three forest types, they prefer primary and secondary forests when more food resources and shelter are available (Carey \& Johnson, 1995; Gray et al., 2019; Rebelo et al., 2019).

Zhang et al. (2020) found that the TD, FD and PD of avian communities in secondary forests were higher than those in primary and plantation forests in the same study region, which was inconsistent with our results. Therefore, different taxa may respond differently to forest conversion. Such an inconsistency may be caused by the higher adaptability of small mammals to forest conversion than birds (Graham et al., 2019). In addition, secondary forests with more plant species, including berry plant, can attract more bird species (Zhang et al., 2020).

\subsection{Phylogenetic and functional structure}

Our study further indicated that random ecological processes were dominant in the assembly of the small mammal communities across different forest types. Our results were different from those reported for the avian communities in Mt. Liangshan, where habitat filtering was the primary mechanism in the primary forest (Zhang et al., 2020). We propose two possible explanations for this result: 1) forest habitats with high productivity and sufficient niches allow the settlement of lineages with different ecological attributes, and 2) small mammals usually have wide niche breadths (strong adaptability), so they are typically more successful in accommodating to forest conversion than other taxa (Wu et al., 2019; Graham et al., 2019). Most of the small mammal species were captured in more than one forest type, and only a few species were found in a single forest type (Appendix). In addition, the phylogenetic structure of the small mammal communities were clustered among the three forest types, and there were no differences in the phylogenetic structure among the three forest types. Our results were different from previous studies that conformed to "assembly rules" (Table S2), as species interact based on their phenotypic similarities and differences, and that phenotypic variation has a basis in evolutionary history (Hanz et al., 2019; Sobral \& Cianciaruso, 2016; Webb et al., 2002; Zhang et al., 2020). The clustered phylogenetic structure in all forest types may be attributed to in situ diversification and low dispersal rates within regions (dispersal filter; Cardillo, 2011), followed by the maintenance of this phylogenetic structure pattern by random ecological processes. Overall, random ecological processes dominated the small mammal communities in forest habitats, and forest conversion had no significant effect on the random ecological processes.

\subsection{Conclusions and management implications}

In our study region, forests conversion does not appear to cause strong changes in diversity and community structures of small mammals. Our results indicated that the establishment of local protected areas and the 
retention of parts of the primary forests is effective in protecting biodiversity, at least for small mammals. However, we still know little about how the other components of the forest ecosystem interact with small mammals. Further work is thus required to determine whether fundamental ecosystem processes in converted forests are altered by changes in resource availability, competitor and carnivorous predator species and abundance, even if the small mammal assemblages remained consistent (Terborgh et al., 2001).

Finally, our results indicated that small mammal diversity in the plantation forests was significantly lower than that in the primary forests, probably due to the lower diversity and abundance of shrubs and understorey vegetation at the plantation forest sites. To finely restore biodiversity, we suggest keeping proper planting distance and avoiding excessive density in the plantation forests, which could increase the diversity of trees, shrubs and understorey vegetation.

\section{ACKNOWLEDEMENTS}

We thank the many people who assisted us in field sampling and data collection. We are grateful to the Meigu Dafengding Nature Reserve and Heizhugou Nature Reserve for their permission to do the research. This work received funding from three organizations: a) The investigation on vertbrate in the Meigu Dafengding Nature Reserves no. 16H0859, b) The investigation on vertbrate in the Heizhugou Nature Reserve no. $17 \mathrm{H} 0757$ and c) the National Natural Science Foundation of China no 31970495.

\section{CONFLICT OF INTEREST}

The authors declare that they have no known competing financial interests or personal relationships that could have appeared to influence the work reported in this paper.

\section{AUTHOR CONTRIBUTION}

Xingcheng He : Experimental design and data collection, Data analysis, Writing-original draft.

Zhixin Wen : Data analysis, Writing-review \& editing.

Dejun Zhang : Experimental design and data collection.

Xudong Yin : Data collection.

Xue Chen : Data collection.

Jianghong Ran : Experimental design, Writing-review \& editing, Supervision.

\section{DATA AVAILABILITY STATEMENT}

Data for this article are available at the Dayad: https://doi.org/10.5061/dryad.j3tx95xfs

Fig. 1 Map of the study area and its position within Sichuan Province (the red area in the inset). The circles represent the fixed sample sites, and the circles with crosses represent the sample sites not surveyed due to landslides in March 2018. The sample sites set up as supplements are represented by triangles in the figure.

Fig. 2 a, b and c Rarefaction curves of small mammal diversity across the three forest types (blue shaded regions, $95 \%$ confidence intervals).

Fig. 3 Small mammals taxonomic, phylogenetic and functional diversity at the site scale and landscape scale for the three forest types. Black dots are outliers. Different letters indicate significant differences.

Fig. 4 Multidimensional scaling plot of small mammal assemblages among the three forest types

Fig. 5 Small mammals standardized effect size of mean phylogenetic distances and standardized effect size of mean functional distances at the site scale and landscape scale for the three forest types. Black dots are outliers. Different letters indicate significant differences. ${ }^{*}$ indicates significantly different from 0. 
Fig. 6 Small mammals taxonomic, phylogenetic and functional diversity at the site scale and landscape scale for the three forest types across three seasons. Black dots are outliers. Different letters indicate significant differences among the three forest types.

Fig. 7 Small mammals standardized effect size of mean phylogenetic distances and standardized effect size of mean functional distances at the site scale and landscape scale for the three forest types across three seasons. Black dots are outliers. Different letters indicate significant differences among the three forest types. ${ }^{*}$ indicates significantly different from 0 .

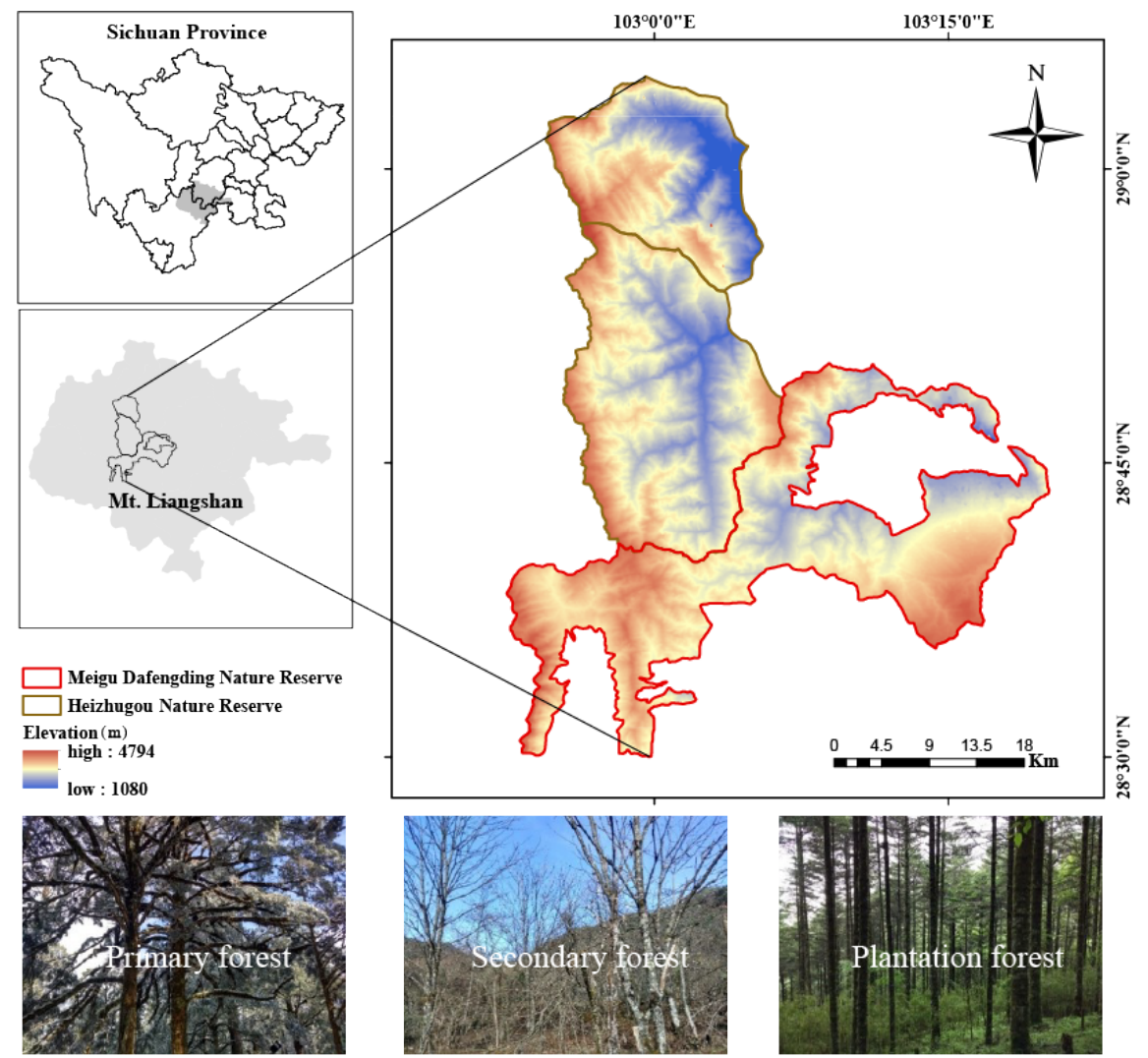

Fig. 1 Map of the study area and its position within Sichuan Province (the red area in the inset). The circles represent the fixed sample sites, and the circles with crosses represent the sample sites not surveyed due to landslides in March 2018. The sample sites set up as supplements are represented by triangles in the figure.
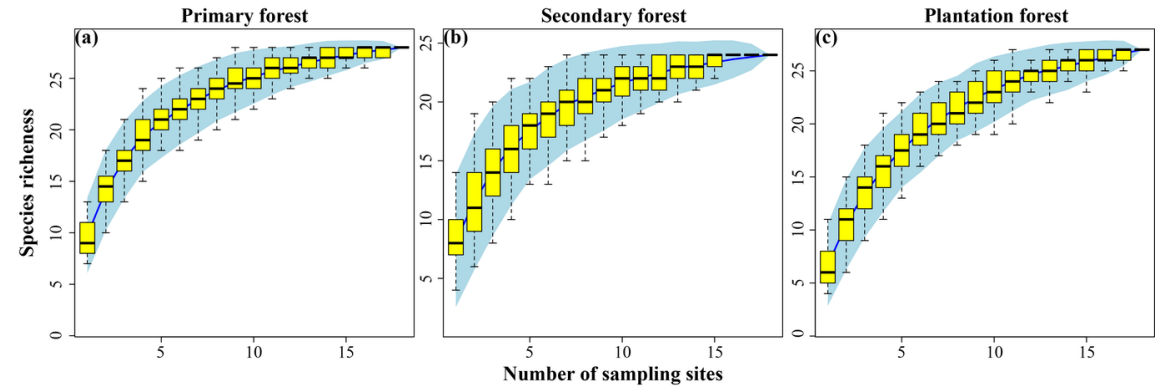
Fig. 2 a, b and c Rarefaction curves of small mammal diversity across the three forest types (blue shaded regions, $95 \%$ confidence intervals).
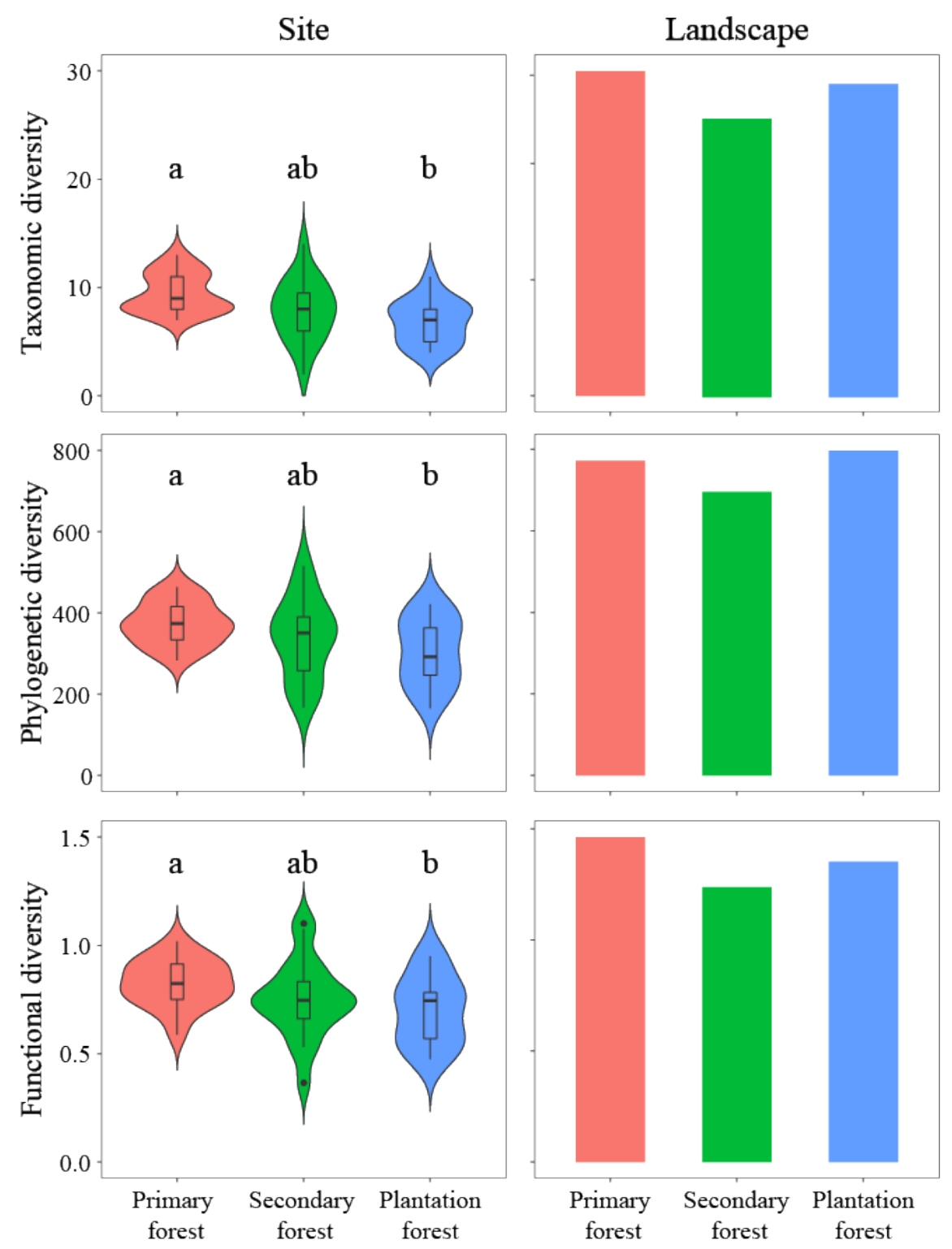

Fig. 3 Small mammals taxonomic, phylogenetic and functional diversity at the site scale and landscape scale for the three forest types. Black dots are outliers. Different letters indicate significant differences. 


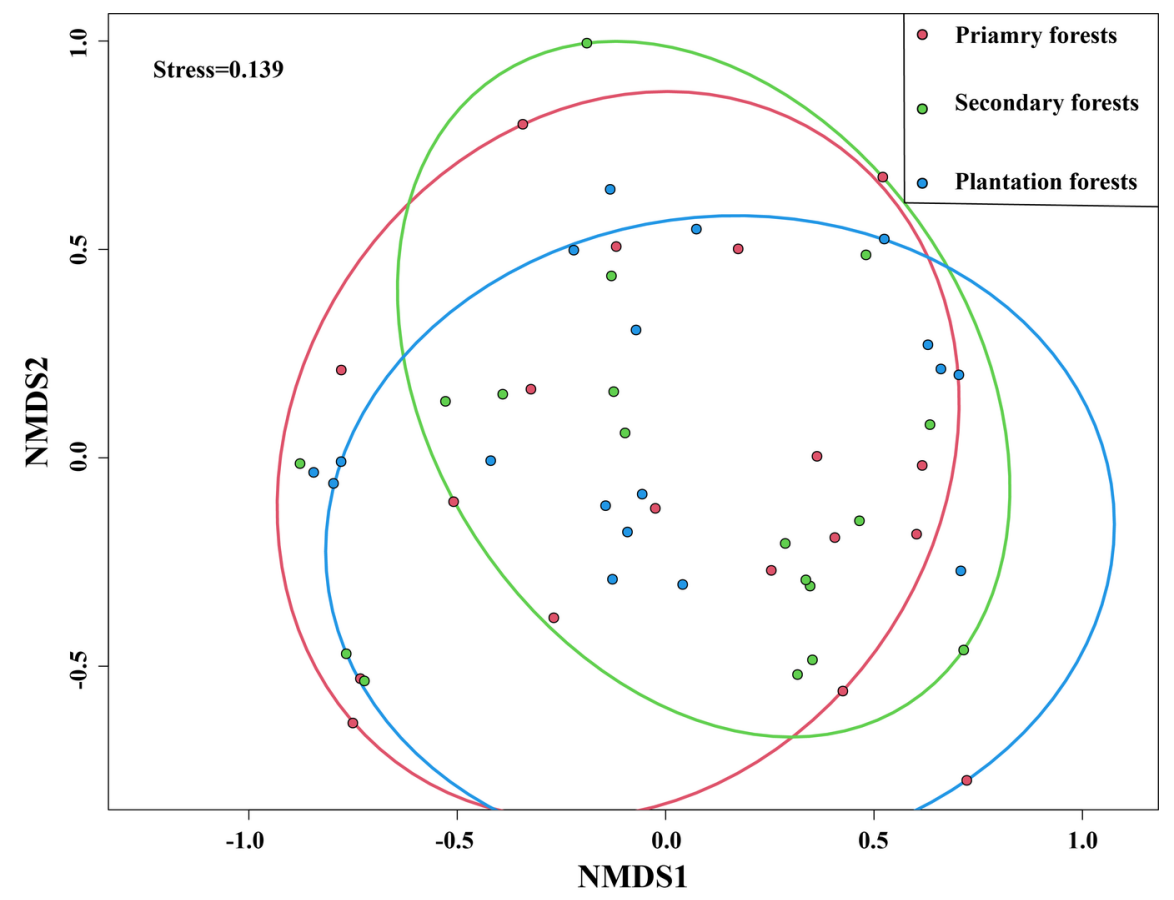

Fig. 4 Multidimensional scaling plot of small mammal assemblages among the three forest types
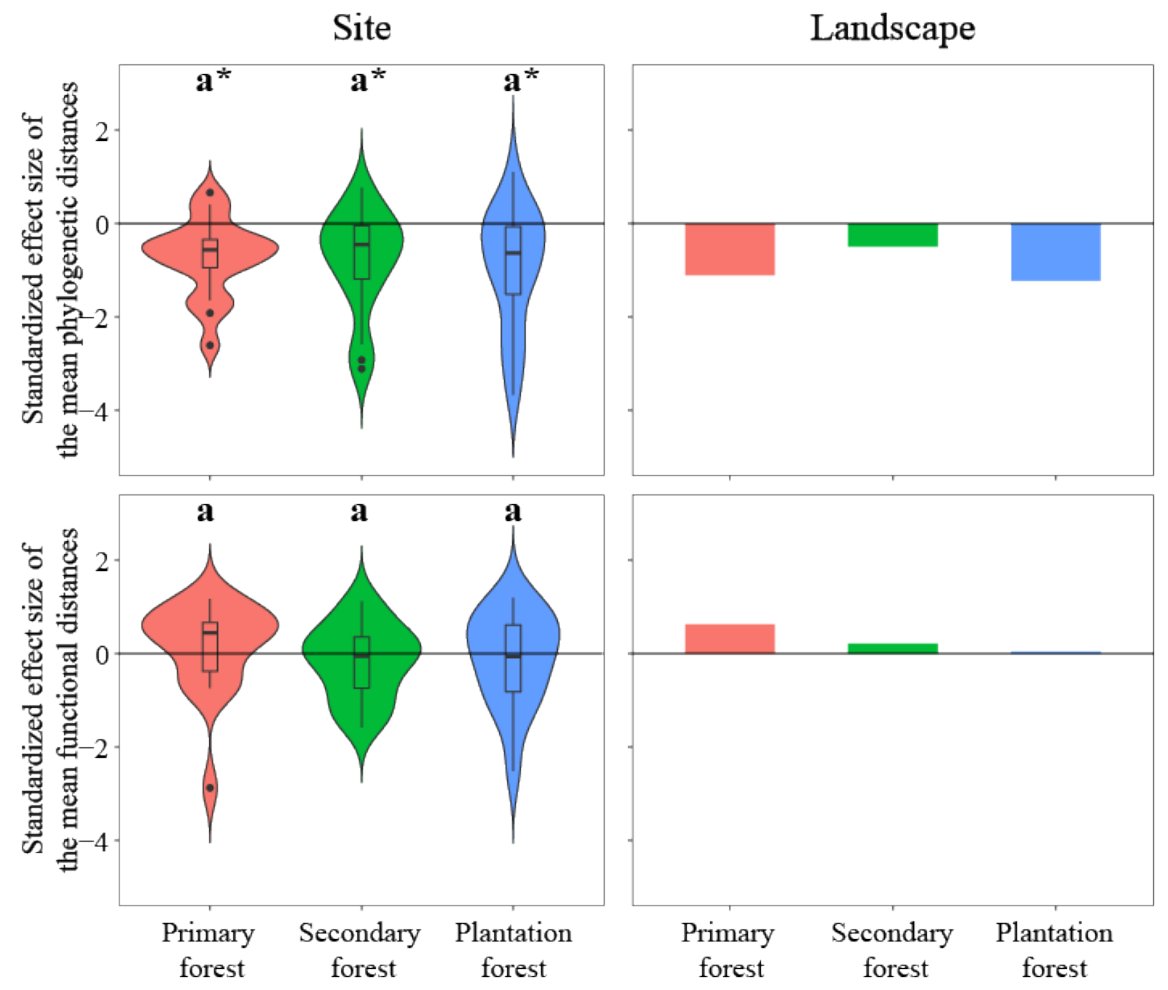

Fig. 5 Small mammals standardized effect size of mean phylogenetic distances and standardized effect size 
of mean functional distances at the site scale and landscape scale for the three forest types. Black dots are outliers. Different letters indicate significant differences. ${ }^{*}$ indicates significantly different from 0.
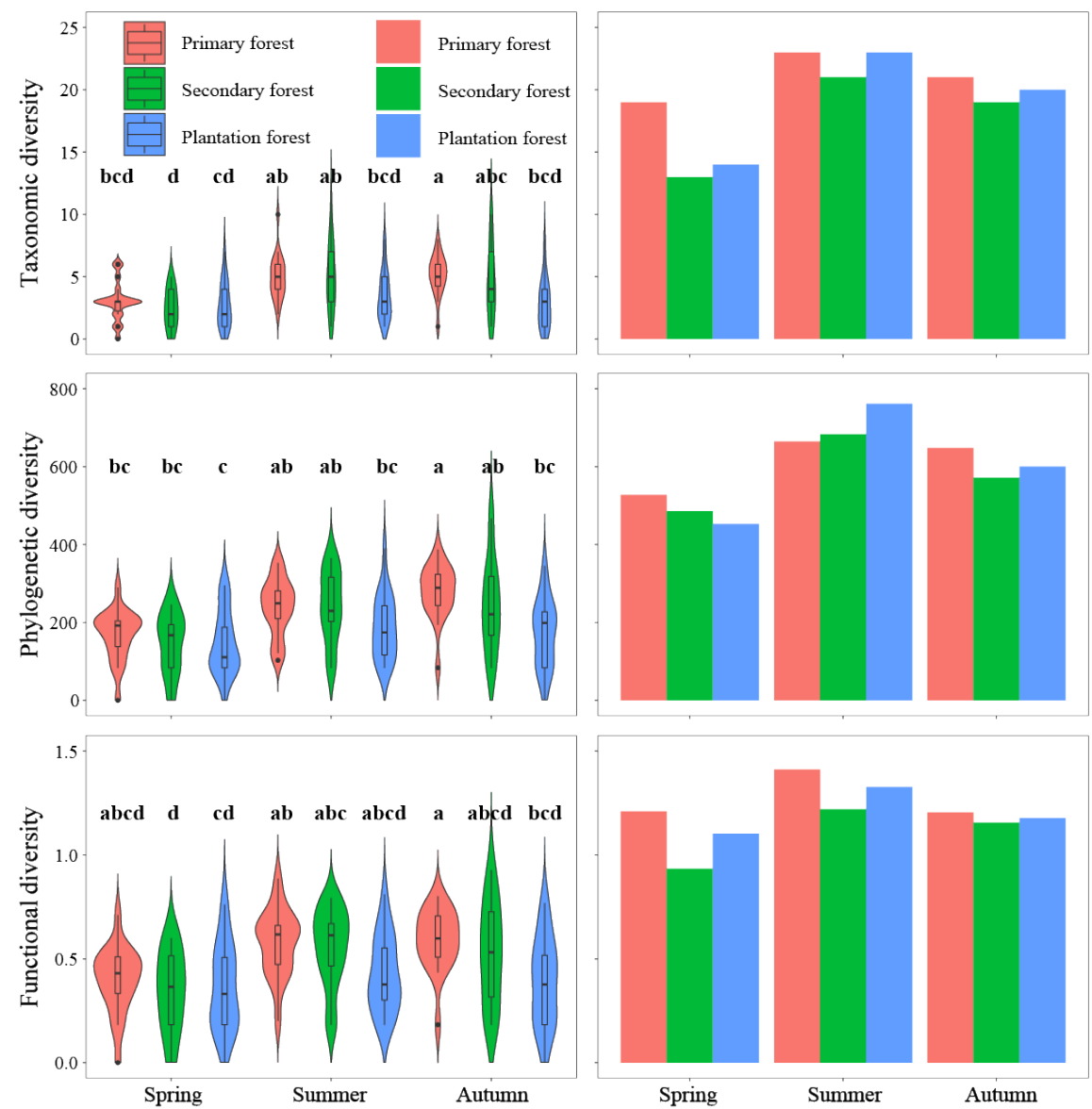

Fig. 6 Small mammals taxonomic, phylogenetic and functional diversity at the site scale and landscape scale for the three forest types across three seasons. Black dots are outliers. Different letters indicate significant differences among the three forest types. 


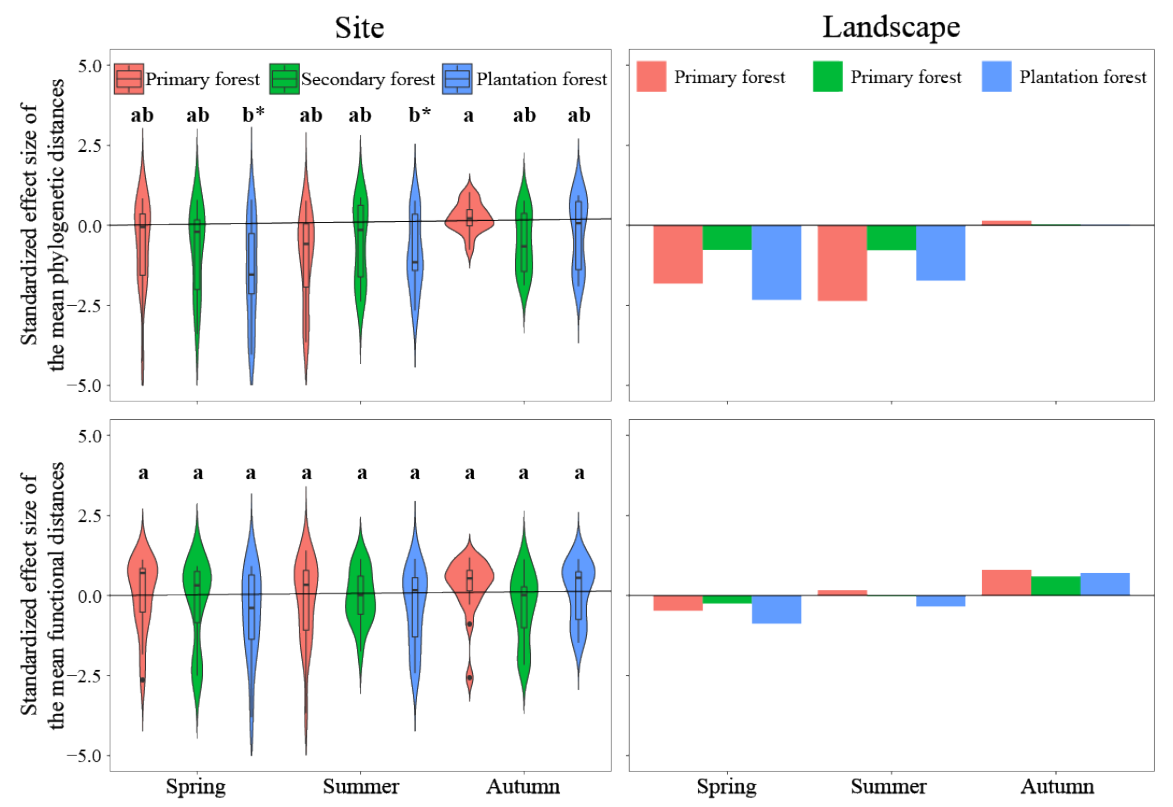

Fig. 7 Small mammals standardized effect size of mean phylogenetic distances and standardized effect size of mean functional distances at the site scale and landscape scale for the three forest types across three seasons. Black dots are outliers. Different letters indicate significant differences among the three forest types. * indicates significantly different from 0.

\section{References}

Blomberg, S. P., Garland, T., \& Ives, A. R. (2003). Testing for phylogenetic signal in comparative data: Behavioral traits are more labile. Evolution, 57 (4), 717-745. doi:10.1111/j.0014-3820.2003.tb00285.x

Bogdziewicz, M., \& Zwolak, R. (2014). Responses of small mammals to clear-cutting in temperate and boreal forests of Europe: a meta-analysis and review. European Journal of Forest Research , 133 (1), 1-11. doi:10.1007/s10342-013-0726-x

Bernard, H., Fjeldsa. J., \& Mohamed, M. (2009). A case study on the effects of disturbance and conversion of tropical lowland rain forest on the non-volant small mammals in north Borneo: Management implications.Mammal Study , 34 (2),85-96. doi: 10.3106/041.034.0204

Cardillo, M. (2011). Phylogenetic structure of mammal assemblages at large geographical scales: linking phylogenetic community ecology with macroecology. Philosophical Transactions of the Royal Society BBiological Sciences , 366 (1577), 2545-2553. doi:10.1098/rstb.2011.0021

Carey, A. B., \& Johnson, M. L. (1995). Small mammals in managed, naturally young, and old-growth forests. Ecological Applications ,5 (2), 336-352. doi:10.2307/1942026

Chubbs, T. E., \& Trimper, P. G. (1998). The diet of nesting Ospreys, Pandion haliaetus, in Labrador. Canadian Field-Naturalist ,112 (3), 502-505.

Clarke, K. R. (1993). Non-parametric multivariate analyses of changes in community structure. Australian Journal of Ecology ,18(1) : 117-143. doi:10.1111/j.1442-9993.1993.tb00438.x

Davis, M., Faurby, S., \& Svenning, J. C. (2018). Mammal diversity will take millions of years to recover from the current biodiversity crisis.PANS , 115 (44), 11262-11267. doi:10.1073/pnas.1804906115

Dawson, R. D., \& Bortolotti, G. R. (2000). Reproductive success of American Kestrels: The role of prey abundance and weather.Condor , 102 (4), 814-822. doi:10.1650/0010-5422(2000)102[0814:Rsoakt]2.0.Co;2 
Diaz, S., \& Cabido, M. (2001). Vive la difference: plant functional diversity matters to ecosystem processes. Trends in Ecology 83 Evolution , 16 (11), 646-655. doi:10.1016/s0169-5347(01)02283-2

Diaz, S., Purvis, A., Cornelissen, J. H. C., Mace, G. M., Donoghue, M. J., Ewers, R. M., . . . \& Pearse, W. D. (2013). Functional traits, the phylogeny of function, and ecosystem service vulnerability.Ecology and Evolution , 3 (9), 2958-2975. doi:10.1002/ece3.601

Elek, Z., Magura, T., \& Ecology, B. T. J. W. (2001). Impacts of non-native Norway spruce plantation on abundance and species richness of ground beetles (Coleoptera: Carabidae). Web Ecology , 2 (1), 32-32. doi: 10.5194/we-2-32-2001

Ernest, S. K. M., \& Brown, J. H. (2001). Homeostasis and compensation: The role of species and resources in ecosystem stability.Ecology , 82 (8), 2118-2132. doi:10.2307/2680220

Faith, D. P. (1992). Conservation evaluation and phylogenetic diversity.Biological Conservation , 61 (1), 1-10. doi:10.1016/0006-3207(92)91201-3

Faurby, S., Davis, M., Pedersen, R. O., Schowanek, S. D., Antonelli, A., \& Svenning, J.-C. (2018). PHYLACINE 1.2: The Phylogenetic Atlas of Mammal Macroecology. Ecology , 99 (11), 2626-2626. doi:10.1002/ecy.2443

Felton, A., Wood, J., Felton, A. M., Hennessey, B., \& Lindenmayer, D. B. (2008). Bird community responses to reduced-impact logging in a certified forestry concession in lowland Bolivia. Biological Conservation , 141 (2), 545-555. doi:10.1016/j.biocon.2007.11.009

Fritz, S. A., \& Purvis, A. (2010). Selectivity in Mammalian Extinction Risk and Threat Types: a New Measure of Phylogenetic Signal Strength in Binary Traits. Conservation Biology , 24 (4), 1042-1051. doi:10.1111/j.1523-1739.2010.01455.x

Graham, S. I., Kinnaird, M. F., O’Brien, T. G., Vagen, T.-G., Winowiecki, L. A., Truman P. Y., \& Young, H. S. (2019). Effects of land-use change on community diversity and composition are highly variable among functional groups. Ecological Applications ,29 (7), doi:10.1002/eap.1973

Gray, S. M., Roloff, G. J., Dennhardt, A. J., Dotters, B. P., \& Engstrom, T. T. (2019). Within-Patch Structures Influence Small Mammal Abundance in Managed Forests of Northern California, USA. Forest Science, 65 (6), 796-804. doi:10.1093/forsci/fxz037

Grau, H. R., Arturi, M. F., Brown, A. D., \& Acenolaza P. G. (1997). Floristic and structural patterns along a chronosequence of secondary forest succession in Argentinean subtropical montane forests. Forest Ecology E Management , 95 (2), 161-171. doi: 10.1016/S0378-1127(97)00010-8

Hanz, D. M., Boehning-Gaese, K., Ferger, S. W., Fritz, S. A., Neuschulz, E. L., Quitian, M., . . . Schleuning, M. (2019). Functional and phylogenetic diversity of bird assemblages are filtered by different biotic factors on tropical mountains. Journal of Biogeography ,46 (2), 291-303. doi:10.1111/jbi.13489

Heer, K., Helbig-Bonitz, M., Fernandes, R. G., Mello, M. A. R., \& Kalko, E. K. V. (2015). Effects of land use on bat diversity in a complex plantation-forest landscape in northeastern Brazil.Journal of Mammalogy , 96 (4), 720-731. doi: 10.1093/jmammal/gyv068

Hilbert, J., \& Wiensczyk, A. (2007). Old-growth definitions and management: A literature review. vol 8. Vancouver: Canadian Institute for Studies in Publishing Press Simon Fraser University.

Hughes, A. C. (2017). Understanding the drivers of Southeast Asian biodiversity loss. Ecosphere, 8 (1). doi:10.1002/ecs2.1624

Hurlbert, A. H., \& Haskell, J. P. (2003). The effect of energy and seasonality on avian species richness and community composition.American Naturalist , 161 (1), 83-97. doi:10.1086/345459 
Jian, J., Jiang, H., Zhou, G., Jiang, Z., Yu, S., Peng, S., .. W Wang, J. (2011). Mapping the vegetation changes in giant panda habitat using Landsat remotely sensed data. International Journal of Remote Sensing , 32 (5), 1339-1356. doi: 10.1080/01431160903547981.

Jiang, Z. G., Ma, Y., Wu, Y., Wang, Y. X., Zhou, K. Y., .. Feng, Z. J. (2015). China's mammal diversity and geographic distribution. Beijing:The Science Press. (in chinese)

Kembel, S. W., Cowan, P. D., Helmus, M. R., Cornwell, W. K., Morlon, H., Ackerly, D. D., \& Webb, C. O. (2010). Picante: R tools for integrating phylogenies and ecology. Bioinformatics , 26 (11), 1463-1464. doi:10.1093/bioin forma tics/btq166

Kosulic, O., Hamrik, T., \& Lvoncik, S. (2020). Patterns of change in the species composition of vascular plants during different succession stages and management intensity of a lowland floodplain forest.Biologia, 75 (11), 1801-1813. doi:10.2478/s11756-020-00536-5

Lindenmayer, D. B., Wood, J., McBurney, L., Blair, D., \& Banks, S. C. (2015). Single large versus several small: The SLOSS debate in the context of bird responses to a variable retention logging experiment.Forest Ecology and Management, 339 , 1-10. doi:10.1016/j.foreco.2014.11.027

Liang, C. P., Dai, Q.,Z \& Li, C. (2008). A simple and conservation method for measuring and monitoring small terrestrial vertebrates: drift fences and pitfall traps. Sichuan Journal of Zoology ,28 (02), 273-275. doi:210.75.237.14/handle/351003/19153

Luque, C., Gers, C., Lauga, J., Mariano, N., Wink, M., \& Legal, L. (2007). Analysis of forestry impacts and biodiversity in two Pyrenean forests through a comparison of moth communities (Lepidoptera, Heterocera). Insect Science , 14 (4), 323-338. doi:10.1111/j.1744-7917.2007.00159.x

Magura, T., Bogyo, D., Mizser, S., Nagy, D. D., \& Tothmeresz, B. (2015). Recovery of ground-dwelling assemblages during reforestation with native oak depends on the mobility and feeding habits of the species. Forest Ecology and Management, 339 , 117-126. doi:10.1016/j.foreco.2014.12.015

Manuwal, D. A., \& Huff, M. H. (1987). Spring and winter bird populations in a douglas-fire forest sere. Journal of Wildlife Management, 51 (3), 586-595. doi:10.2307/3801273

Meiners, S. J., \& Pickett, S. T. A. (1999). Changes in community and population responses across a forestfield gradient. Ecography ,22 (3), 261-267. doi:10.1111/j.1600-0587.1999.tb00501.x

Mittermeier R. A., Gil P. R., Hoffmann M., Pilgrim J., Brooks T., Mittermeier C. G., \& Lamoreux J. (2005). Fonseca GABD. Hotspots revisited: Earth's biologically richest and most endangered terrestrial ecoregions. Revised ed. Chicago: University of Chicago Press.

Montano-Centellas, F. A., McCain, C., \& Loiselle, B. A. (2020). Using functional and phylogenetic diversity to infer avian community assembly along elevational gradients. Global Ecology and Biogeography ,29 (2), 232-245. doi:10.1111/geb.13021

Morales-Hidalgo, D., Oswalt, S. N., \& Somanathan, E. (2015). Status and trends in global primary forest, protected areas, and areas designated for conservation of biodiversity from the Global Forest Resources Assessment 2015. Forest Ecology and Management , 352 , 68-77. doi:10.1016/j.foreco.2015.06.011

Orme, D., Freckleton, R., Thomas, G., \& Petzoldt, T. (2013). Caper: Comparative analysis of phylogenetics and evolution in R. R package Version 1.0.1.

Oksanen, J., Blanchet, F. G., Kindt, R., Legendre, P., Minchin, P. R., O’Hara, R. B., .. Wagner, H. (2012). vegan: Community Ecology Package. R package Version 2.0-5.

Partel, M., Zobel, M., Zobel. K., \& VanderMaarel, E. (1996). The species pool and its relation to species richness: Evidence from Estonian plant communities. Oikos , 75 (1), 111-117. doi:10.2307/3546327 
Pedersen, A. O., Yoccoz, N. G., Ims, R. A.\& Sigurdsen, T. (2010).Forest Ecology and Management, 260 (3), 331-338. doi:10.1016/j.foreco.2010.04.020

Rebelo, A. J., Rebelo, A. G., Rebelo, A. D., \& Bronner, G. N. (2019). Effects of alien pine plantations on small mammal community structure in a southern African biodiversity hotspot. African Journal of Ecology , 57 (2), 212-225. doi:10.1111/aje.12591

Revell, L. J., Harmon, L. J., \& Collar, D. C. (2008). Phylogenetic Signal, Evolutionary Process, and Rate. Systematic Biology, 57 (4), 591-601. doi:10.1080/10635150802302427

Sobral, F. L., \& Cianciaruso, M. V. (2016). Functional and phylogenetic structure of forest and savanna bird assemblages across spatial scales.Ecography , 39 (6), 533-541. doi:10.1111/ecog.00903

Suchomel, J., Purchart, L., \& Cepelka, L. (2012). Structure and diversity of small-mammal communities of lowland forests in the rural central European landscape. European Journal of Forest Research ,131 (6), 1933-1941. doi:10.1007/s10342-012-0644-3

Suchomel, J., Purchart, L., Cepelka, L., \& Heroldova, M. (2014). Structure and diversity of small mammal communities of mountain forests in Western Carpathians. European Journal of Forest Research ,133 (3), 481-490. doi:10.1007/s10342-013-0778-y

Sun, J., Wen, Z. X., Feijo, A., Cheng, J. L., Wang, Y. Q., Li, S., . . . Yang, Q. S. (2020). Elevation patterns and critical environmental drivers of the taxonomic, functional, and phylogenetic diversity of small mammals in a karst mountain area. Ecology and Evolution ,10 (19), 10899-10911. doi:10.1002/ece3.6750

Tsirogiannis, C., \& Sandel, B. (2016). PhyloMeasures: a package for computing phylogenetic biodiversity measures and their statistical moments. Ecography , 39 (7), 709-714. doi:10.1111/ecog.01814

Tinya, F., Kovacs, B., Bidlo, A., Dima, B., Kiraly, I. Kustzegi, G., .. Odor, P. (2021). Environmental drivers of forest biodiversity in temperate mixed forests - A multi-taxon approach. The Science of the total environment , 795 , 148720. doi:10.1016/j.scitotenv.2021.148720

Umetsu, F., \& Pardini, R. (2007). Small mammals in a mosaic of forest remnants and anthropogenic habitats-evaluating matrix quality in an Atlantic forest landscape. Landscape Ecology , 22 (4), 517-530. doi:10.1007/s10980-006-9041-y

Urgoiti, J., Muñoz, A., Espelta, J. M., \& Bonal, R. J. I. Z. (2018). Distribution and space use of seeddispersing rodents in central Pyrenees: implications for genetic diversity, conservation and plant recruitment. Integrative Zoology , 13 (3), 307-318. doi:10.1111/1749-4877.12301

Webb, C. O., Ackerly, D. D., McPeek, M. A., \& Donoghue, M. J. (2002). Phylogenies and community ecology. Annual Review of Ecology and Systematics, 33 , 475-505. doi:10.1146/annurev.ecolsys.33.010802.150448

Williams, S. E., Shoo, L. P., Henriod, R., \& Pearson, R. G. (2010). Elevational gradients in species abundance, assemblage structure and energy use of rainforest birds in the Australian Wet Tropics bioregion. Austral Ecology , 35 (6), 650-664. doi:10.1111/j.1442-9993.2009.02073.x

Wilman, H., Belmaker, J., Simpson, J., de la Rosa, C., Rivadeneira, M. M., \& Jetz, W. (2014). EltonTraits 1.0: Species-level foraging attributes of the world's birds and mammals. Ecology , 95 (7), 2027-2027. doi:https://doi.org/10.1890/13-1917.1

Yan, J. (2005). A study on economy sustainable development in Sichuan poverty areas. Chengdu: Sichuan University. (in chinese)

Yang, X. F., Xie, W. H., Tao, S. L., Li, J. N., Xiao, Z. S. (2015). Effects of forest succession on rodent diversity in the Dujiangyan region, Southwest China. Chinese Journal of Ecology , 34(9), 2546-2552. doi:CNKI:SUN:STXZ.0.2015-09-022 (in chinese) 
Wu, N., Zhong, J., Lei, B., Xie, Z., \& Zhou, Y. (2019). Community reestablishment and poor body conditions of small mammal assemblages in subtropical afforested ecosystems. Ecological Engineering ,135 , 1-7. doi:10.1016/j.ecoleng.2019.04.031

Zhang, T., Chen, X., Wu, Y., \& Ran, J. (2020). Diversity and structure of bird communities in contrasting forests of the Hengduan Mountains, China. Biodiversity and Conservation, 29 (13), 3739-3755. doi:10.1007/s10531-020-02047-w

Zhao, D., Yang, C., Ma, J., Zhang, X., \& Ran, J. (2020). Vertebrate prey composition analysis of the Pallas's cat (Otocolobus manul) in the Gongga Mountain Nature Reserve, based on fecal DNA. Mammalia ,84 (5), 449-457. doi:10.1515/mammalia-2018-0144
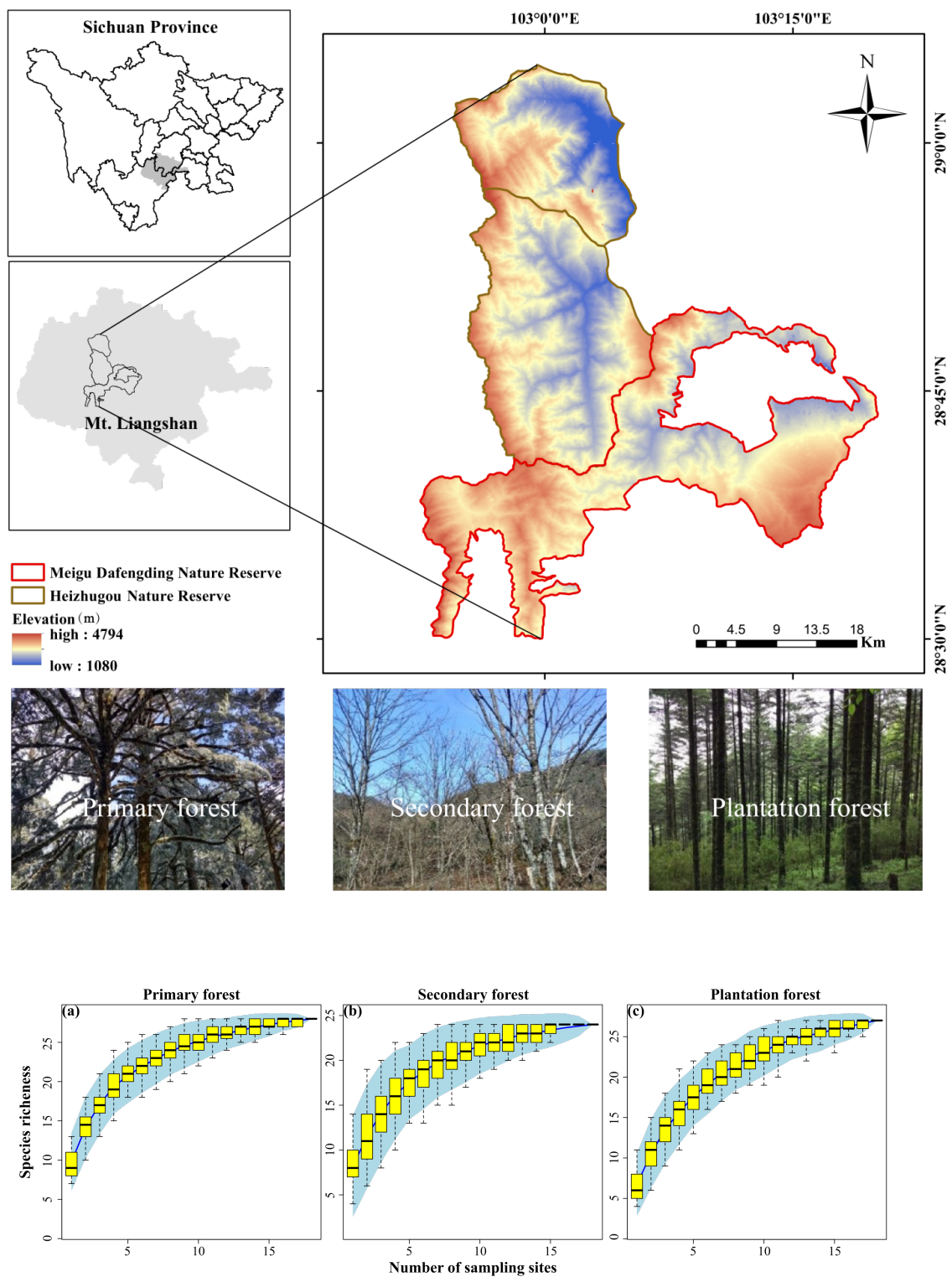
Site
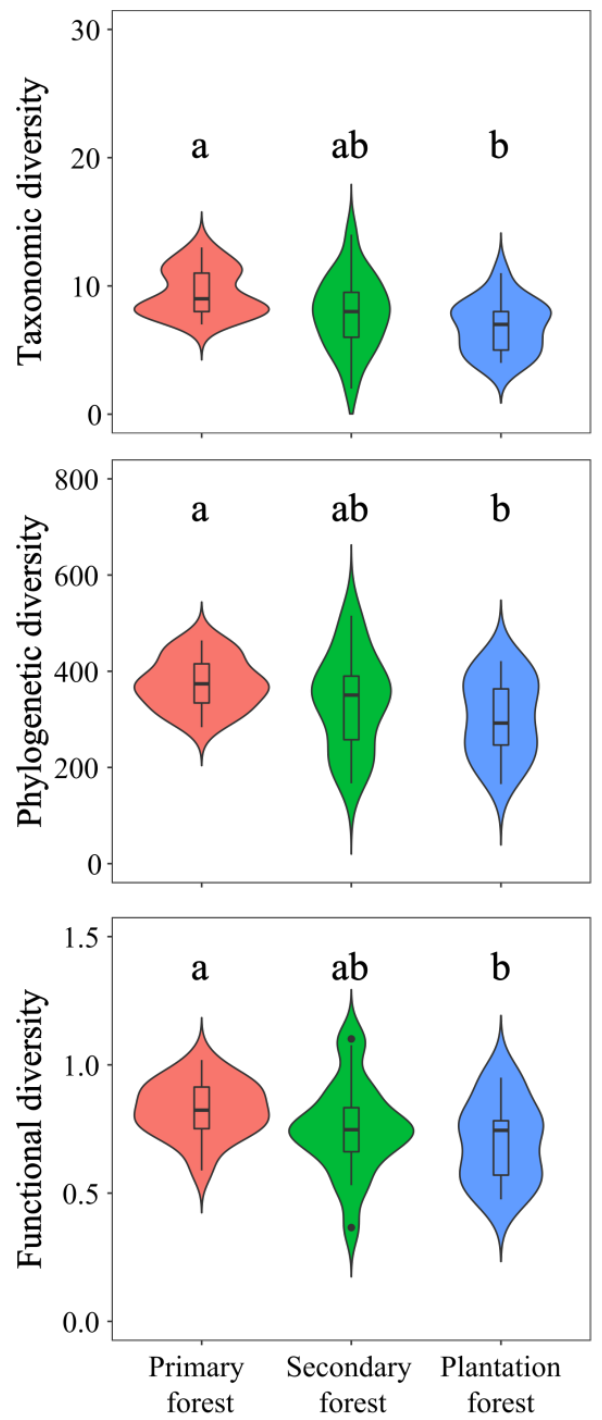

Landscape
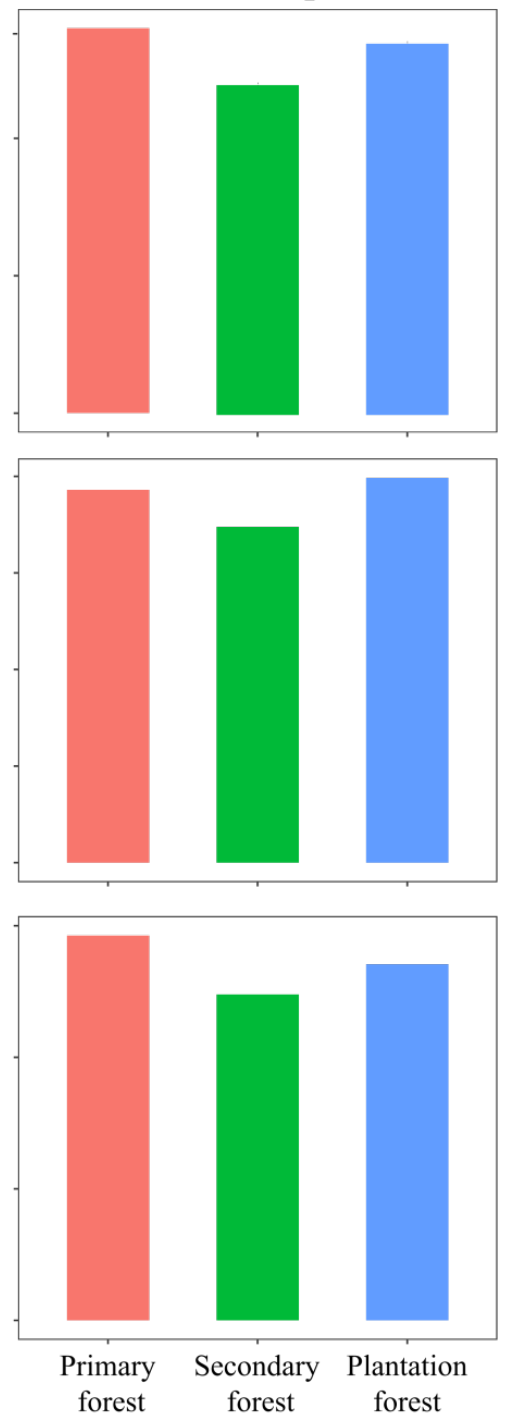

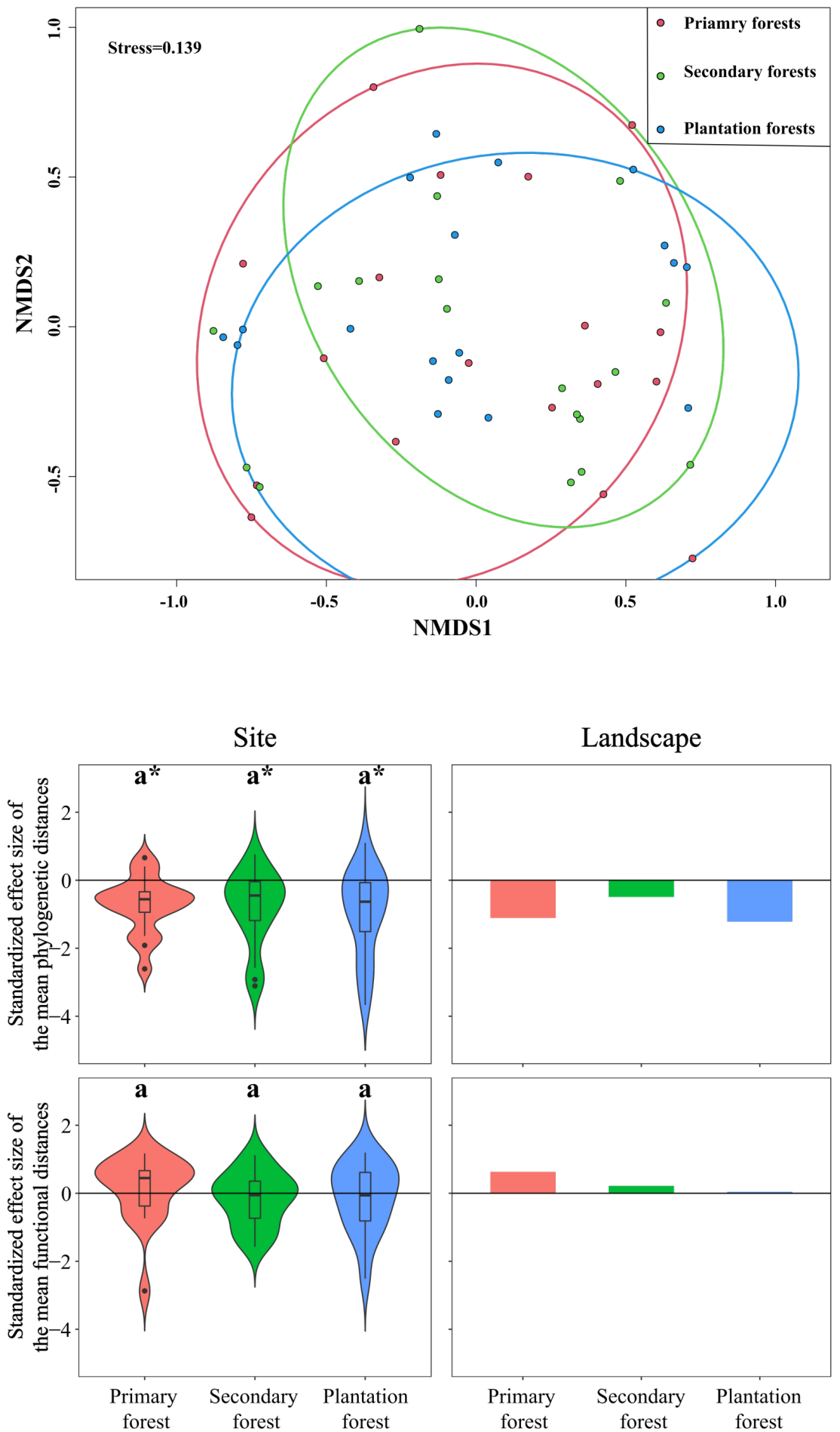

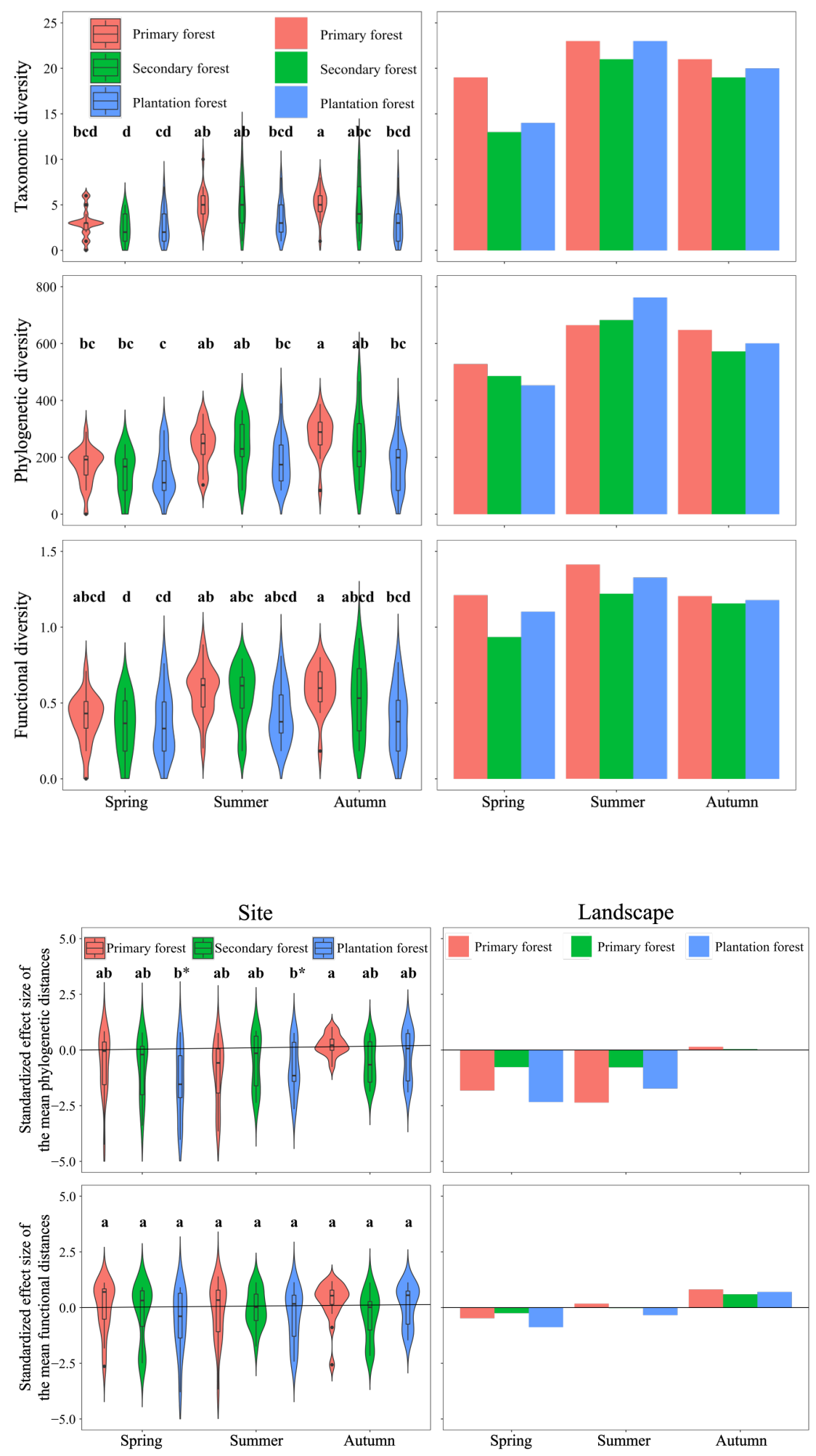